\title{
Planejamento em BIM 4D comparado ao planejamento tradicional
}

Uma das dimensões da metodologia BIM, o planejamento BIM 4D vem como um pujante diferencial quando comparado ao tratamento convencional de longos anos dado a este tema na construção civil. De maneira a tornar esta comparação vista no ambiente prático, este trabalho realizou um planejamento de uma construção de uma casa popular, com apenas um pavimento térreo, adicionando a simulação visual do cronograma em formato gráfico de Gantt/PERT-CPM no software Navisworks, o que é a nova ideia do planejamento em BIM 4D, e elencou as vantagens em relação ao processo tradicional. Com isso, o presente artigo, pelo fato de ser um pontapé inicial, busca atrair olhares de um extenso público-alvo, que vai desde estudantes de engenharia civil interessados na área do planejamento, a profissionais atuantes que almejam ingressar neste novo mundo da dimensão BIM 4D, acompanhados também do interesse dos donos de empresas construtoras, os quais buscam sempre pelo melhor controle do planejamento, gerenciamento e, consequentemente, dos custos de suas obras. No entanto, para se chegar ao objetivo final, passos prévios foram tomados, como a modelagem BIM 3D, no Revit, da disciplina de arquitetura, com a posterio vinculação desta com a de estrutura, de modo a servir como auxílio para a modelagem desta última; extração dos quantitativos de ambas as áreas no mesmo software para, depois, criar a planilha de orçamentação dos serviços. Além disso, concebeu-se o cronograma do projeto proposto no software MS Project e, com o intuito de estimar a duração em dias de cada atividade, elaborou-se o quadro de duração de atividades e de recursos. Posteriormente, exportaram-se os modelos 3D e o cronograma de barras para o Navisworks e, com as configurações necessárias neste, a simulação gráfica tornou-se possivel. Por fim, o respectivo projeto atingiu o seu objetivo, evidenciando-se importantes vantagens em relação ao planejamento convencional, e pode-se dizer que contribui para a realização de mais pesquisas dentro da área BIM 4D, além de congregar outras dimensões, como 4D (tempo) e 5D (custo), para novos estudos.

Palavras-chave: Planejamento; BIM; BIM 4D.

\section{BIM 4D planning compared to traditional planning}

One of the BIM methodology dimensions, BIM 4D scheduling comes with a thriving differential when compared to old years conventional treatment given to this topic on civil construction. In order to make this comparison viewed in a practical environment, this paper performed a common house construction 's schedulling, with only a ground floor, adding the visual simulation of schedule in Gantt/PERT-CPM chart format using Navisworks software, which is the new idea of planning in BIM 4D, and listed the advantages compared to traditional process. Thereby, the present article, due to the fact of being a kickoff, seeks to attract glances of a broad target audience, that goes from civil engineering students interested in planning area, to active professionals who long for joining this new world of BIM $4 \mathrm{D}$ dimension, followed by owners of construction companies' interestings as well, who always wish they better control scheduling, management and, as a result, the budget of their constructions. However, to achieve the final goal, previous steps were taken, such as architecture discipline BIM 3D modeling, in Revit, with, afterwards, the linking between this one with structure discipline, in order to be useful for this last modeling; these areas' material take off in the same software to, later, create a budgeting spreadsheet of services. Moreover, the proposed design`s schedule was conceived in MS Project software and, with the aim to estimate each task's duration in days, the activities and resources' duration framework was made. Later on, 3D modelings and Gantt Chart Bars were exported to Navisworks and, after all needed settings on this, graphic simulation became possible. Lastly, the respective design achieved its goal, showing important advantages compared to conventional planning, and it can be said that it contributes to performances of more researches in BIM 4D area, and besides to gather other dimensions, like 4D (time) and 5D (cost), for new studies.

Keywords: Planning; BIM; BIM 4D

Topic: Engenharia de Construção Civil

Reviewed anonymously in the process of blind peer.
Received: 10/04/2020

Approved: $\mathbf{3 0 / 0 7 / 2 0 2 0}$
David Passos Barbosa Dias

Universidade Federal de Sergipe, Brasil

http://lattes.cnpq.br/6235348159773571

http://orcid.org/0000-0002-5318-8794

davidpassos1234@gmail.com

\section{Referencing this:}

DIAS, D. P. B.. Planejamento em BIM 4D comparado ao planejamento tradicional. Engineering Sciences, v.8, n.2, p.26-44, 2020. DOI: http://doi.org/10.6008/CBPC2318-3055.2020.002.0004 


\section{INTRODUÇÃO}

Um dos grandes entraves da construção civil atualmente é visualizar o planejamento da obra em três dimensões (RODRIGUES, 2012, citado por SILVA, 2017). Através de um bom planejamento, melhorias em relação aos planos de ataque na obra podem ser buscadas, de modo a cumprir com os prazos definidos de entrega, realizar uma gestão construtiva eficaz e trabalhar dentro do orçamento previsto (MAGALHÃES et al., 2018)

A construção civil, por ser um setor ainda bem arcaico, mas complexo perante as outras indústrias, sofre com o excesso de desperdícios e prejuízos ocasionados, principalmente, com a falta de planejamento e controle da execução de um empreendimento, o que interfere, consequentemente, em elevados custos, os quais não eram previstos, e em atraso em relação ao prazo planejado.

O planejamento tradicional sofre o risco, muitas vezes, dos problemas listados no parágrafo acima. Dentre as desvantagens estão a não visualização e não simulação de cenários variados (SILVA, 2017). Além disso, ele demanda esforço na visualização e interpretação mental de um cronograma e no avanço físico das etapas de execução, o que depende da experiência e do nível do conhecimento do projeto do respectivo profissional (SILVA, 2017). Outrossim, para se antecipar a conflitos de espaço-tempo, é necessária uma análise detalhada do cronograma (SILVA, 2017).

No que diz respeito ao planejamento em BIM 4D, as vantagens em relação ao convencional são relevantes. Uma delas é a possibilidade de revisão de vários panoramas, de forma a decidir sobre o melhor método construtivo, o qual seja mais lucrativo e economize tempo. Outro grande proveito é permitir a visualização do progresso da obra através de uma visualização gráfica, com as atividades atreladas ao cronograma (SILVA, 2017).

\section{REVISÃO TEÓRICA}

\section{BIM}

BIM (Building Information Modeling) é um processo de modelagem da informação da construção, traduzido como "Modelo de Informação da Construção", e que utiliza um conceito engenhoso e paramétrico de representação digital, no qual se podem gerar informações passíveis de serem usufruídas para tomada de decisões (MAGALHÃES et al., 2018).

Segundo Manzione (2013, citado por MAGALHÃES et al. 2018), o BIM é um processo de gestão da informação, em que os modelos elaborados se fazem compreensíveis no ambiente virtual através de regras e parâmetros. Os recursos deste processo possibilitam a melhoria dos métodos de controle de informações de obras e projetos, como também descomplicam o compartilhamento de informações entre os profissionais participantes (MAGALHÃES et al., 2018).

BIM, ao contrário do que muito se pensa, não é um software próprio, mas um processo abrangedor de múltiplos programas, podendo ser chamados de ferramentas BIM (MAGALHÃES et al., 2018). Ainda em relação ao conceito deste modelo, Succar (2019, citado por MAGALHÃES et al., 2018) define-o como um 
"conjunto integrado de políticas, processos e tecnologias, que gera uma metodologia para gerenciar os projetos e seus dados ao longo do ciclo de vida do edifício".

\section{BIM na construção civil}

O uso de ferramentas computacionais, como o BIM, se apresenta como a nova geração de ferramentas CAD (Computer Aided Design) aplicadas ao ciclo de vida do projeto, como forma de gerenciar informações (CALDAS et al., 2015). Os profissionais atuantes na área da arquitetura, engenharia e construção precisam ajustar-se a estas novas ferramentas, em rumo à colaboração, interoperabilidade e reutilização da informação (CALDAS et al., 2015).

O BIM pode ser categorizado em dimensões que abrangem a 2D até a 7D (CALDAS et al., 2015). A 2D é referente aos desenhos simples, como plantas, cortes e elevações, o que diverge da dimensão 3D, a qual traz um modelo digital 3D (CALDAS et al., 2015). Por sua vez, a 4D relaciona o tempo na sequência de fases com a construção 3D (CALDAS et al., 2015). A 5D adiciona o custo (orçamento) (CALDAS et al., 2015). A 6D, por conseguinte, abarca o ciclo de vida e gerenciamento energético (CALDAS et al., 2015). Por fim, a 7D refere-se a questões concernentes à segurança (MOTOAN, 2015, citado por CALDAS et al., 2015).

Um conceito importante dentro deste processo é a interoperabilidade, à qual é a habilidade do câmbio de dados entre softwares, colaborando na automação e fluxos de trabalho (EASTMAN et al., 2011). Para o usufruto das plataformas BIM, esta definição é necessária, pois arquivos eletrônicos demandam o trânsito em diferentes softwares e a assimilação por todos eles, sem extinção de informações (CALDAS et al., 2015).

Na Figura 1, o objetivo do BIM é bem resumido, pois ele foca em solucionar o projeto na fase preliminar e nos seus detalhes, de modo a minimizar os custos nas etapas seguintes (CAMPESTRINI et al., 2015). Assim, é importante o adiantamento da informação, justamente para garantir a rapidez do processo de decisão de um empreendimento (CAMPESTRINI et al., 2015).

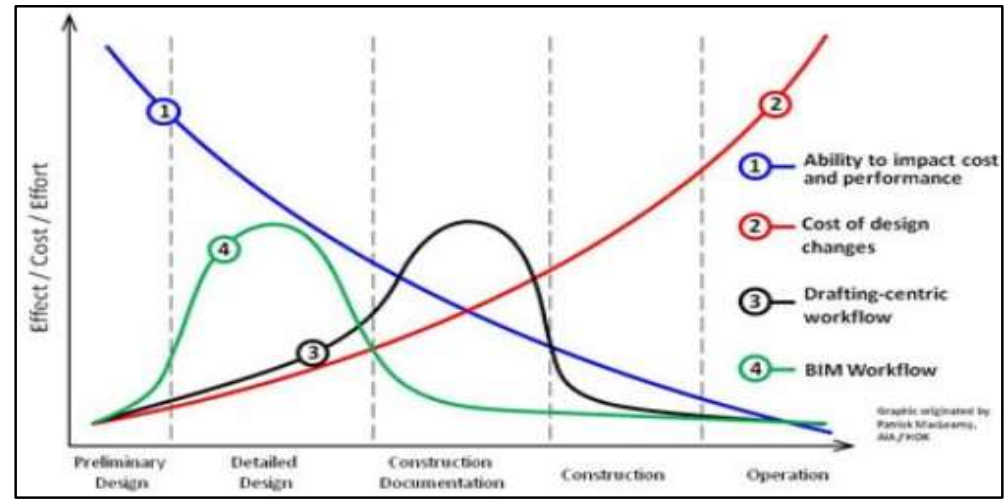

Figura 1: Curva de MacLeamy Fonte: Campestrini et al. (2015).

\section{Planejamento de obras}

O conceito de planejamento é estabelecido como processo gerencial que abrange os objetivos definidos e a determinação de procedimentos indispensáveis para alcançá-los, de modo que é eficaz somente ao ser realizado conjuntamente com o controle (FORMOSO et al., 2001). Sendo assim, não existe controle 
sem planejamento, e vice-versa (FORMOSO et al., 2001). Há dois tipos de cronogramas, que são o cronograma em redes e o cronograma em barras (SILVA, 2017).

Em relação ao cronograma de barras, o mais utilizado nos empreendimentos construtivos é o Gráfico de Gantt, também conhecido como Diagrama de Barras. O motivo para isso é justamente a facilidade de execução e, principalmente, de visualização por técnicos e leigos, o que enobrece o relacionamento inicial entre contratante e contratado (QUEIROZ, 2001). Entretanto, esse diagrama não apresenta certos benefícios trazidos pelo diagrama de rede Pert/CPM (Program evaluation and review technique/Critical Path Method), como a inserção de sucessoras e predecessoras, de forma a interdepender as etapas construtivas; a simplicidade de reprogramações, o que é tão comum nas obras; e o detalhamento de etapas ou serviços em atividades de interesse singular (QUEIROZ, 2001). Devido a essas desvantagens, os diagramas de Gantt, são parcialmente proveitosos para o planejamento e controle de projetos (MAYERLE, 2014).

Esse diagrama é desenvolvido em planilha própria (Figura 2) e constituído de uma coluna, a qual exibe as etapas construtivas do empreendimento; e da representação do tempo de cada etapa em linhas horizontais, nas quais estão inseridas as barras representantes do prazo, e os percentuais mensais a serem executados de cada etapa (QUEIROZ, 2001).

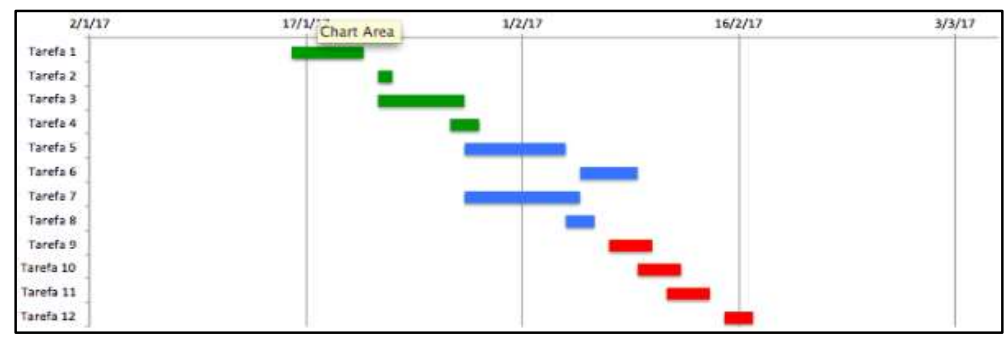

Figura 2: Gráfico de Gantt Fonte: smartsheet (2019).

No que diz respeito ao cronograma de redes, o tipo principal dele é a Rede PERT/CPM (Program Evaluation and Review Technique/Critical Path Method), representada pela Figura 3. Essa rede é a representação gráfica de um projeto, programa ou empreendimento, no qual a sequência lógica do planejamento é exposta, assim como o elo de interdependência (predecessoras e sucessoras) entre as múltiplas atividades que formam o projeto (QUEZADO, 1999). Nela, exibem-se as durações das atividades, as datas de início e fim de cada uma delas, e também os recursos utilizados por elas, de maneira a permitir, sobretudo, uma análise da otimização de tempo e custo (QUEZADO, 1999).

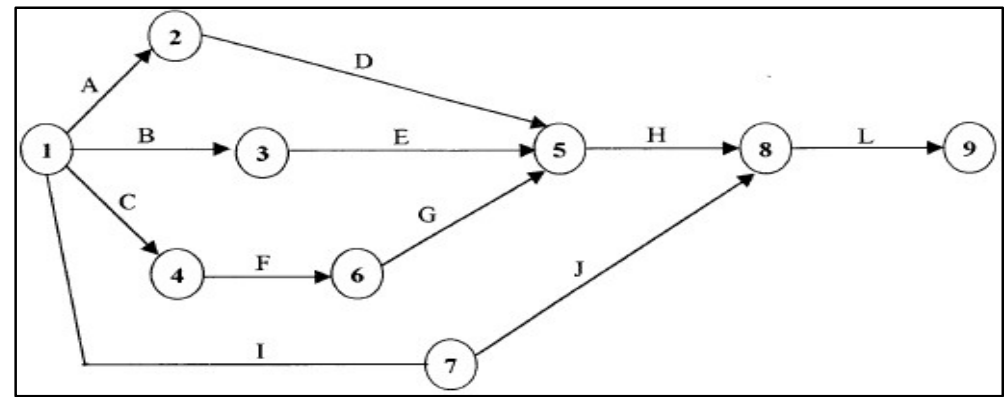

Figura 3: Rede de atividades PERT/COM. Fonte: Quezado (1999).

Em um planejamento de um empreendimento construtivo, de modo a se aproveitar das vantagens 
de cada método, a tática utilizada é a combinação entre o gráfico de Gantt e a rede PERT/CPM. A justificativa disso é que, de acordo com Gehbauer et al. (2002), os cronogramas de barras puros, entre algumas inconveniências apresentadas anteriormente, também não possibilitam nenhum dado sobre o avanço de uma atividade dentro de um determinado processo, e também não evidenciam claramente a conexão lógica entre as atividades. Do mesmo modo, o gráfico de Gantt, em sua forma simples, não leva em conta as folgas e não expõe o caminho crítico (MATTOS, 2010). Este é, segundo Mattos (2010), "a sequência de atividades que concorrem para a determinação da duração total"; e aquelas, conforme o mesmo autor, as atividades não críticas, ou seja, aquelas que "possuem alguma margem de tempo que lhes garante determinada flexibilidade". Portanto, com o intuito de solucionar as limitações do diagrama de barras, planejadores elaboraram uma versão requintada dele, introduzindo dados obtidos da rede PERT/CPM, concebendo-se, então, o cronograma integrado Gantt-PERT/CPM (MATTOS, 2010). Por fim, é este o cronograma a ser abordado neste trabalho.

\section{Quadro Duração-Recursos}

Ao identificar as atividades de um planejamento, deve-se partir para a definição de suas respectivas durações (MATTOS, 2010). A duração é o dado numérico de tempo em função do cronograma gerado, sendo, portanto, um dos incumbentes pela obtenção do prazo da obra (MATTOS, 2010). Durações mal definidas podem prejudicar integralmente o planejamento, tornando-o inútil na prática para quem gerenciar a obra (MATTOS, 2010).

É importante frisar que duração é sempre uma estimativa, estando, por isso, sujeita a uma margem de erro, que pode ser ínfima para atividades repetitivas, costumeiras e bem familiares; ou relevante para novos serviços ou para aqueles sem disposição de dados históricos (MATTOS, 2010). Em sequência, a duração deve sempre se referir a dias (ou semanas, etc.) úteis, em outras palavras, aqueles em que se trabalha efetivamente (MATTOS, 2010).

Outro ponto é que não se pode estimar a duração aleatoriamente, apesar de estar envolta em imprecisões (MATTOS, 2010). Assim, para fins de planejamento de obras, as composições de custos unitários do orçamento são a origem dos elementos para a estimativa do tempo (MATTOS, 2010). As composições de custos unitários, por sua vez, são tabelas que abarcam os insumos do serviço proposto, com seus competentes índices, razão unitária de produção (RUP) ou coeficientes de consumo; custo unitário e custo total (MATTOS, 2010). O índice é a incidência de cada insumo na execução de uma unidade do serviço e sempre apresentado em unidade de tempo por unidade de trabalho (MATTOS, 2010).

Em relação à produtividade, em sendo definida como a quantidade de unidades de trabalho por intervalo de tempo especificado, usualmente hora, ela seria o inverso do índice (MATTOS, 2010). Com este entendimento em mente, ou seja, de índice e produtividade, pode-se calcular a duração das atividades integrantes do planejamento (MATTOS, 2010).

Outra questão é que há dois tipos de pensamento: definir a equipe e calcular a duração da atividade, ou firmar a duração e calcular a equipe necessária (MATTOS, 2010). Neste artigo, foi adotada a segunda 
postura. Assim sendo, tem-se as seguintes fórmulas ao se fixar a duração (MATTOS, 2010): Usando índice: QTDE DE RECURSOS = (QTDE x ÍNDICE) / (DURAÇÃO x JORNADA); Usando produtividade: QTDE DE RECURSOS = QTDE / (PRODUTIVIDADE x DURAÇÃO x JORNADA). Para uma obra com diversos serviços, um bom conselho, de acordo com Mattos (2010), é convergir os cálculos de duração e equipe (quantidade de recursos) em uma única planilha, chamada de Quadro Duração-Recursos, conforme apresentada na Figura 4.

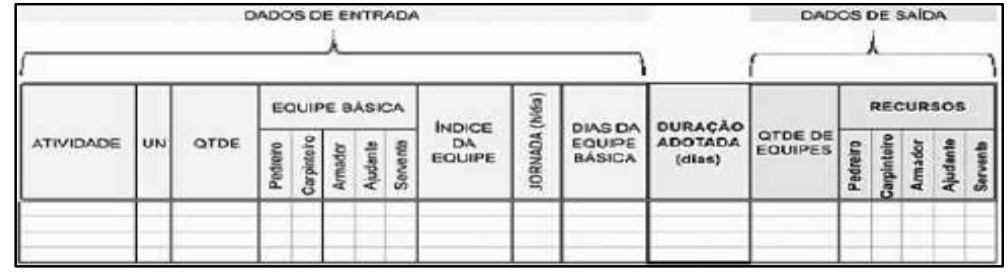

Figura 4: Configuração básica do QDR. Fonte: Mattos (2010).

De acordo com a tabela-base, os dados de entrada são oriundos do orçamento da obra, como quantitativo, equipe básica e índice da equipe (MATTOS, 2010). Ao se adotar uma duração adequada a determinada atividade, computa-se a quantidade de recursos apta a executar determinada tarefa no tempo atribuído (MATTOS, 2010). Pondera-se ainda que o índice da equipe é representado pelo insumo principal de mão de obra, pois é ele que pauta o ritmo da produção (MATTOS, 2010).

\section{Planejamento em BIM 4D}

O planejamento BIM 4D é o planejamento tradicional aliado à modelagem tridimensional, sendo ambos relacionados no software Autodesk Navisworks neste trabalho, o que possibilita a realização de um planejamento virtual e compará-lo ao real (campo). Esta dimensão BIM possibilita algumas competências, como a visualização do processo da construção, maior entendimento do cronograma, identificação de erros e potenciais empecilhos antes da execução (BRITO et al., 2015). Em outras aplicações da modelagem 4D, Biotto et al. (2013) citam benesses tais quais a facilidade de se visualizar erros de sequenciamento das atividades, conflitos entre equipamentos, o limite físico do canteiro de obras, atividades com risco aos operários e possibilidades de ingerências entre equipamentos e instalações de canteiros. A literatura a respeito da aplicação do modelo BIM 4D é ampla e, portanto, merece atenção especial, eis que a indústria da construção civil necessita entender melhor e amplamente como aplicar modelos BIM para a gerência de projetos (HARTMANN et al., 2008, citados por BRITO et al., 2015).

\section{METODOLOGIA}

\section{Objeto de estudo}

A metodologia utilizada neste trabalho baseia-se no comparativo entre o planejamento tradicional e o BIM 4D, cujo diferencial é a visualização gráfica do primeiro, tornando-se mais claro inclusive para aqueles que não fazem parte do corpo técnico e dando uma maior precisão dos planos de ataque para redução de custo e de atividades que não agregam valor. 


\section{Coleta de dados}

O que se fez primeiramente foi a elaboração de um desenho arquitetônico de uma casa simples, com $37 \mathrm{~m}^{2}$ de área construída, 2 quartos, 1 cozinha, 1 sala, 1 banheiro e com apenas 1 pavimento térreo, baseada em uma das plantas do sítio eletrônico 'construindodecor', no Software Autodesk Revit 2019, de maneira a simplificar o trabalho, pois o objetivo não é a concepção detalhada de um planejamento, mas simplesmente a comparação entre um planejamento convencional e o feito em BIM 4D. Para tal, somente duas disciplinas foram abordadas: estrutural e arquitetura, deixando de lado as complementares, como hidrossanitária e elétrica. Após a etapa de modelagem 3D do projeto arquitetônico da casa, abriu-se um novo arquivo para modelagem da etapa estrutural no mesmo aplicativo. Com isso, vinculou-se o arquitetônico no estrutural, através da tab Insert - panel Link - Link Revit.

A próxima etapa foi a elaboração do cronograma no Software MS Project 2007, cuja duração de cada atividade foi estabelecida através do quadro duração-recursos, baseado na tabela de Mattos (2010) e construído no Microsoft Office Excel 2019, por meio do uso dos índices de cada recurso de trabalho retirado da composição dos serviços da tabela de preços do SINAPI e ORSE.

Por fim, cada valor de custo dos serviços das disciplinas de estrutura e arquitetônico foi retirado do site ORSE, o qual possui valores de custo de serviços tanto da fonte do próprio ORSE, como do SINAPI, atualizados mensalmente. Com isso, através do quantitativo de materiais extraído automaticamente do Revit, pôde-se obter o custo total de cada serviço e, assim, o custo global deste projeto. Entretanto, é importante frisar que o foco deste trabalho foi a etapa de planejamento (BIM 4D), e não o de orçamentação (BIM 5D). Nesta, é preferível o uso de softwares especializados, como o Vico ou o Orçafascio, visto que há a inclusão de outros custos e os valores, durante o processo construtivo, vão sendo modificados, além de outros fatores cruciais para a elaboração de uma orçamentação completa, o que não se faz somente com o uso de um software de planejamento como o Navisworks.

\section{Tratamento de dados}

Nesta etapa, será descrito como todos os dados discriminados foram organizados para, por fim, iniciar a simulação visual do processo de planejamento. Após a modelagem 3D, todos os quantitativos foram automaticamente gerados e levados ao Excel, onde, ao final, formou-se uma tabela com os quantitativos de cada serviço, custos unitários retirados da fonte SINAPI e, quando a descrição de determinado serviço desta fonte não era tão fiel ao modelado no Revit, a fonte ORSE foi utilizada. É necessário realçar que o período para os custos desta base de dados é de julho/2019-1. Em seguida, partiu-se para a elaboração do cronograma Gantt/PERT-CPM no MS Project 2007.

Na sequência, iniciou-se o processo de transferência das modelagens 3D das disciplinas de arquitetura e de estruturas, e do cronograma para o software Navisworks, de modo a simular a sequência de atividades. Assim, com as configurações findadas, pôde-se executar a simulação do planejamento proposto e fazer as comparações em relação ao processo convencional. 


\section{RESULTADOS E DISCUSSÃO}

Primeiramente, apresenta-se abaixo a modelagem em 3D do plano arquitetônico do presente trabalho:

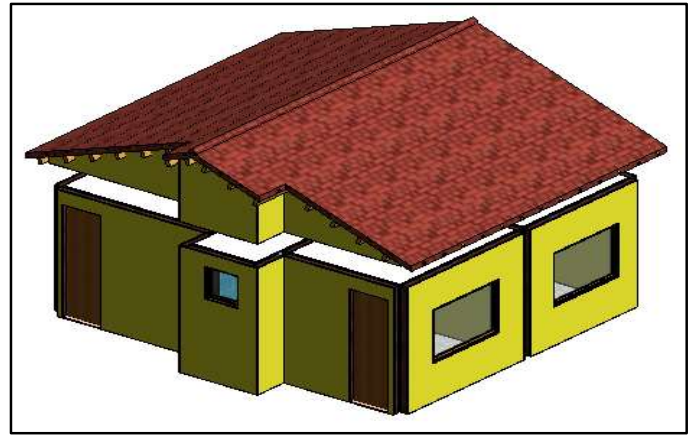

Figura 5: Modelagem 3D arquitetônico.

Em seguida, apresenta-se a modelagem do plano estrutural do projeto, sendo posteriormente ilustrada a vinculação entre os dois planos 3D, ver figura 6.

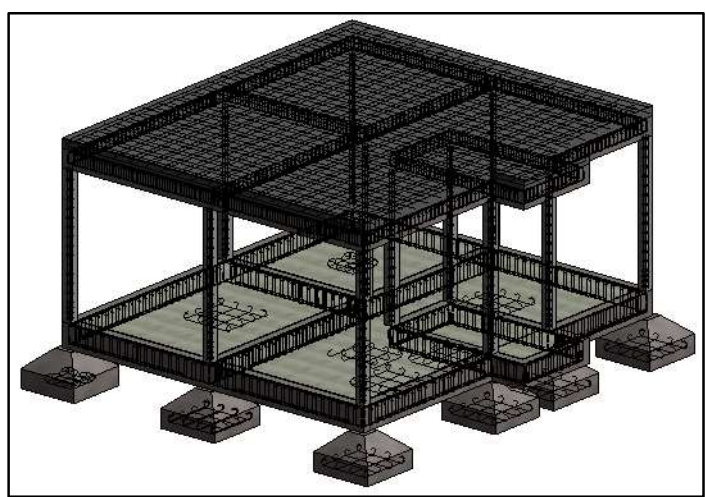

Figura 6: Modelagem 3D estrutural.

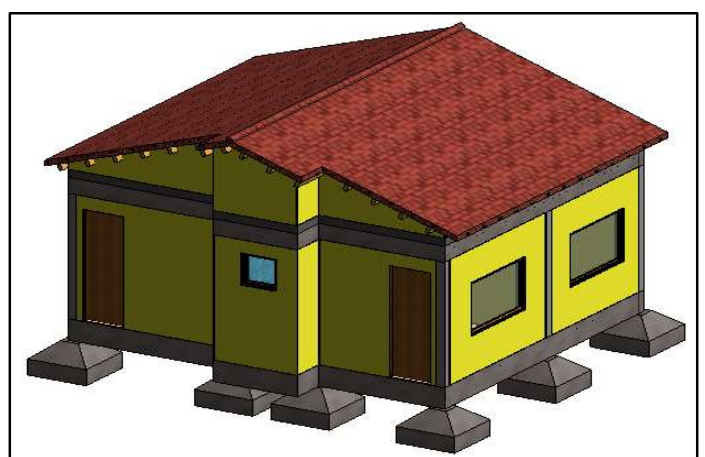

Figura 7: Vínculo 3D arquitetônico-estrutural.

Após ambos os modelos prontos, partiu-se para a extração de quantitativos dos materiais no Revit e, por fim, preparou-se a tabela orçamentária dos serviços, conforme se ilustra na figura 7.

Tabela 1: Planilha de orçamento de serviços de arquitetura e estrutura - Base SINAPI/ORSE - julho 2019/1.

\begin{tabular}{|c|c|c|c|c|c|}
\hline & SERVIÇO & $\begin{array}{l}\text { UN } \\
\text { ID } \\
\text { AD } \\
\text { E }\end{array}$ & $\begin{array}{l}\text { QUA } \\
\text { NTID } \\
\text { ADE }\end{array}$ & $\begin{array}{l}\text { CUST } \\
\text { O } \\
\text { UNITÁ } \\
\text { RIO }\end{array}$ & $\begin{array}{l}\text { Soma de } \\
\text { CUSTO } \\
\text { TOTAL }\end{array}$ \\
\hline ESTR & & & & & R\$\$ \\
\hline UTUR & & & & & 40.099, \\
\hline A & & & & & 77 \\
\hline Cober & & & & & $\mathbf{R} \mathbf{S}$ \\
\hline tura & & & & & $\begin{array}{l}\text { 13.197, } \\
08\end{array}$ \\
\hline Laje & & & & & $\begin{array}{l}\mathrm{RS} \\
13.197 \\
08\end{array}$ \\
\hline 92267 & FABRICAÇÃO DE FÔRMA PARA LAJES, EM CHAPA DE MADEIRA COMPENSADA RESINADA, E = 17 & $\mathrm{~m}^{2}$ & 37,0 & $\mathrm{R} \$$ & $\mathrm{R} \$$ \\
\hline $\begin{array}{l}\text { /SINA } \\
\mathrm{PI}\end{array}$ & MM. AF_12/2015 & & 0 & 25,14 & 930,18 \\
\hline 92481 & MONTAGEM E DESMONTAGEM DE FÔRMA DE LAJE MACIÇA COM ÁREA MÉDIA MENOR OU IGUAL & $m^{2}$ & 37,0 & $\mathrm{R} \$$ & $\mathrm{R} \$$ \\
\hline $\begin{array}{l}\text { /SINA } \\
\mathrm{PI}\end{array}$ & A 20 M², PÉ-DIREITO SIMPLES, EM MADEIRA SERRADA, 1 UTILIZAÇÃO. & & 0 & $\begin{array}{l}195,5 \\
4\end{array}$ & $7.234,98$ \\
\hline 92725 & CONCRETAGEM DE VIGAS E LAJES, FCK=20 MPA, PARA LAJES MACIÇAS OU NERVURADAS COM USO & $\mathrm{m}^{3}$ & 5,55 & $\mathrm{R} \$$ & $\mathrm{R} \$$ \\
\hline /SINA & DE BOMBA EM EDIFICAÇÃO COM ÁREA MÉDIA DE LAJES MENOR OU IGUAL A $20 \mathrm{M}^{2}$ - & & & 337,2 & $1.871,90$ \\
\hline $\mathrm{PI}$ & LANÇAMENTO, ADENSAMENTO E ACABAMENTO. AF_12/2015 & & & 8 & \\
\hline 92771 & ARMACCÃO DE LAJE DE UMA ESTRUTURA CONVEÑCIONAL DE CONCRETO ARMADO EM UM & $\mathrm{Kg}$ & 488 & $\mathrm{R} \$$ & $\mathrm{RS}$ \\
\hline
\end{tabular}




\begin{tabular}{|c|c|c|c|c|c|}
\hline $\begin{array}{l}\text { /SINA } \\
\text { PI }\end{array}$ & $\begin{array}{l}\text { EDIFÍCIO DE MÚLTIPLOS PAVIMENTOS UTILIZANDO AÇO CA-50 DE 10,0 MM - MONTAGEM. } \\
\text { AF_12/2015 }\end{array}$ & & 41 & 6,47 & $3.160,01$ \\
\hline Pav. & & & & & R\$ \\
\hline Térre & & & & & 16.851, \\
\hline o & & & & & 49 \\
\hline Baldr & & & & & R\$ \\
\hline ames & & & & & $5.532,4$ \\
\hline & & & & & 2 \\
\hline 96542 & FABRICAÇÃO, MONTAGEM E DESMONTAGEM DE FÔRMA PARA VIGA BALDRAME, EM CHAPA DE & $\mathrm{m}^{2}$ & 30,9 & $\mathrm{R} \$$ & $\mathrm{R} \$$ \\
\hline $\begin{array}{l}\text { /SINA } \\
\mathrm{PI}\end{array}$ & MADEIRA COMPENSADA RESINADA, E=17 MM, 4 UTILIZAÇÕES. AF_06/2017 & & 5 & 66,06 & $2.044,56$ \\
\hline 96543 & ARMAÇÃO DE BLOCO, VIGA BALDRAME E SAPATA UTILIZANDO AÇO CA-60 DE 5 MM - MONTAGEM. & $\mathrm{Kg}$ & 201, & $\mathrm{R} \$$ & $\mathrm{R} \$$ \\
\hline $\begin{array}{l}\text { /SINA } \\
\mathrm{PI}\end{array}$ & AF_06/2017 & & 37 & 13,21 & $2.660,10$ \\
\hline 96557 & CONCRETAGEM DE BLOCOS DE COROAMENTO E VIGAS BALDRAMES, FCK=30 MPA, COM USO DE & $\mathrm{m}^{3}$ & 2,29 & $\mathrm{R} \$$ & $\mathrm{R} \$$ \\
\hline /SINA & BOMBA? LANÇAMENTO, ADENSAMENTO E ACABAMENTO. AF_06/2017 & & & 361,4 & 827,77 \\
\hline $\mathrm{PI}$ & & & & 7 & \\
\hline Concr & & & & & $\mathrm{R} \$$ \\
\hline eto & & & & & 557,00 \\
\hline magro & & & & & \\
\hline 94974 & CONCRETO MAGRO PARA LASTRO, TRAÇO 1:4,5:4,5 (CIMENTO/AREIA MÉDIA/BRITA 1) - PREPARO & $\mathrm{m}^{3}$ & 1,53 & $\mathrm{R} \$$ & $\mathrm{R} \$$ \\
\hline /SINA & MANUAL. AF_07/2016 & & & 364,0 & 557,00 \\
\hline $\mathrm{PI}$ & & & & 5 & \\
\hline Pilare & & & & & $\mathbf{R} \mathbf{S}$ \\
\hline $\mathbf{s}$ & & & & & $3.443,4$ \\
\hline & & & & & 6 \\
\hline 92408 & FABRICAÇÃO, MONTAGEM E DESMONTAGEM DE FÔRMA DE PILARES RETANGULARES E & $\mathrm{m}^{2}$ & 16,9 & $\mathrm{R} \$$ & $\mathrm{R} \$$ \\
\hline /SINA & ESTRUTURAS SIMILARES COM ÁREA MÉDIA DAS SEÇÕES MENOR OU IGUAL A 0,25 M², PÉ-DIREITO & & 2 & 168,4 & $2.850,17$ \\
\hline $\mathrm{PI}$ & SIMPLES, EM MADEIRA SERRADA, 1 UTILIZAÇÃO. AF_12/2015 & & & 5 & \\
\hline 92719 & CONCRETAGEM DE PILARES, FCK = 25 MPA, COM ŪSO DE BALDES EM EDIFICAÇÃO COM SEÇÃO & $\mathrm{m}^{3}$ & 0,63 & $\mathrm{R} \$$ & $\mathrm{R} \$$ \\
\hline /SINA & MÉDIA DE PILARES MENOR OU IGUAL A 0,25 M² - LANÇAMENTO, ADENSAMENTO E ACABAMENTO. & & & 313,3 & 197,38 \\
\hline $\mathrm{PI}$ & AF_12/2015 & & & 0 & \\
\hline 92762 & ARMAÇÃO DE PILAR OU VIGA DE UMA ESTRUTURA CONVENCIONAL DE CONCRETO ARMADO EM & $\mathrm{Kg}$ & 55,8 & $\mathrm{R} \$$ & $\mathrm{R} \$$ \\
\hline$/ / / \mathrm{SIN}$ & UM EDIFÍCIO DE MÚLTIPLOS PAVIMENTOS UTILIZANDO AÇO CA-50 DE 10,0 MM - MONTAGEM. & & 4 & 7,09 & 395,91 \\
\hline API & AF_12/2015 & & & & \\
\hline Vigas & & & & & $\begin{array}{l}\mathrm{R} \$ \\
7.318,6\end{array}$ \\
\hline & & & & & 2 \\
\hline 92266 & FABRICAÇÃO DE FÔRMA PARA VIGAS, EM CHAPA DE MADEIRA COMPENSADA RESINADA, E = 17 & $\mathrm{~m}^{2}$ & 29,0 & $\mathrm{R} \$$ & $\mathrm{R} \$$ \\
\hline /SINA & MM. AF_12/2015 & & 7 & 85,35 & $2.481,12$ \\
\hline $\mathrm{PI}$ & & & & & \\
\hline 92451 & MONTAGEM E DESMONTAGEM DE FÔRMA DE VIGA, ESCORAMENTO COM GARFO DE MADEIRA, & $\mathrm{m}^{2}$ & 29,0 & $\mathrm{R} \$$ & $\mathrm{R} \$$ \\
\hline /SINA & PÉ-DIREITO SIMPLES, EM CHAPA DE MADEIRA RESINADA, 2 UTILIZAÇÕES. AF_12/2015 & & 7 & 109,6 & $3.186,07$ \\
\hline $\mathrm{PI}$ & & & & 0 & \\
\hline 92725 & CONCRETAGEM DE VIGAS E LAJES, FCK=20 MPA, PARA LAJES MACIÇAS OU NERVURADAS COM USO & $\mathrm{m}^{3}$ & 1,72 & $\mathrm{R} \$$ & $\mathrm{R} \$$ \\
\hline /SINA & DE BOMBA EM EDIFICAÇÃO COM ÁREA MÉDIA DE LAJES MENOR OU IGUAL A $20 \mathrm{M}^{2}$ - & & & 337,2 & 580,12 \\
\hline $\mathrm{PI}$ & LANÇAMENTO, ADENSAMENTO E ACABAMENTO. AF_12/2015 & & & 8 & \\
\hline 92762 & ARMAÇÃO DE PILAR OU VIGA DE UMA ESTRUTURA CONVENCIONAL DE CONCRETO ARMADO EM & $\mathrm{Kg}$ & 151, & $\mathrm{R} \$$ & $\mathrm{R} \$$ \\
\hline /SINA & UM EDIFÍCIO DE MÚLTIPLOS PAVIMENTOS UTILIZANDO AÇO CA-50 DE 10,0 MM - MONTAGEM. & & 10 & 7,09 & $1.071,30$ \\
\hline PI & AF_12/2015 & & & & \\
\hline Solo & & & & & $\mathbf{R} \$$ \\
\hline & & & & & 10.051, \\
\hline & & & & & 20 \\
\hline Sapat & & & & & $\mathbf{R} \$$ \\
\hline as & & & & & $9.878,5$ \\
\hline & & & & & 8 \\
\hline 96532 & FABRICAÇÃO, MONTAGEM E DESMONTAGEM DE FÔRMA PARA SAPATA, EM MADEIRA SERRADA, & $\mathrm{m}^{2}$ & 14,1 & $\mathrm{R} \$$ & $\mathrm{R} \$$ \\
\hline /SINA & E=25 MM, 2 UTILIZAÇÕES. AF_06/2017UTILIZAÇÕES. AF_06/2017 & & 6 & 144,2 & $2.041,87$ \\
\hline $\mathrm{PI}$ & & & & 0 & \\
\hline 96543 & ARMAÇÃO DE BLOCO, VIGA BALDRAME E SAPATA UTILIZANDO AÇO CA-60 DE 5 MM - MONTAGEM. & $\mathrm{Kg}$ & 449, & $\mathrm{R} \$$ & $\mathrm{R} \$$ \\
\hline /SINA & AF_06/2017 & & 02 & 13,21 & $5.931,55$ \\
\hline $\mathrm{PI}$ & & & & & \\
\hline 96558 & CONCRETAGEM DE SAPATAS, FCK 30 MPA, COM USO DE BOMBA - LANÇAMENTO, ADENSAMENTO & $\mathrm{m}^{3}$ & 5,10 & $\mathrm{R} \$$ & $\mathrm{R} \$$ \\
\hline /SINA & E ACABAMENTO. AF_11/2016 & & & 373,5 & $1.905,16$ \\
\hline $\mathrm{PI}$ & & & & 6 & \\
\hline Solo & & & & & $\mathbf{R} \$$ \\
\hline comp & & & & & 172,62 \\
\hline actad & & & & & \\
\hline o & & & & & \\
\hline 00070 & EXECUÇÃO DE ATERRO COMPACTADO, SEM CONTROLE DO GRAU DE COMPACTAÇÃO E SEM FORN. & $\mathrm{m}^{3}$ & 11,2 & $\mathrm{R} \$$ & $\mathrm{R} \$$ \\
\hline /ORSE & DE MATERIAL & & 6 & 15,33 & 172,62 \\
\hline ARQU & & & & & $\mathbf{R} \$$ \\
\hline ITETU & & & & & 29.044, \\
\hline RA & & & & & 32 \\
\hline Cober & & & & & $\mathbf{R} \$$ \\
\hline tura & & & & & $5.686,9$ \\
\hline Engine & $\mathbf{S}$ & & & & g e | 34 \\
\hline
\end{tabular}


Pared

03317

/ORSE

87368

/SINA

PI

87522

/SINA

$\mathrm{PI}$

87888

/SINA

PI

88489

/SINA

PI

96135

/SINA

PI

Telha

do

92541

/SINA

PI

94201

/SINA

$\mathrm{PI}$

94221

/SINA

PI

Pav.

Térre

Forro

96109

/SINA

PI

Janela

01768

/ORSE

84846

/SINA

PI

Piso

05013

/ORSE

87263

/SINA

PI

87372

/SINA

PI

87258

/SINA

PI

Pared

e

03317

/ORSE

87368

/SINA

PI

87398

/SINA

REBOCO ESPECIAL DE PAREDE 2CM COM ARGAMASSA TRAÇO T1 - 1:3 (CIMENTO / AREIA)

ARGAMASSA TRAÇO 1:1,5:7,5 (CIMENTO, CAL E AREIA MÉDIA) PARA EMBOÇO/MASSA ÚNICA/ASSENTAMENTO DE ALVENARIA DE VEDAÇÃO, PREPARO MANUAL. AF_06/2014

ALVENARIA DE VEDAÇÃO DE BLOCOS CERÂMICOS FURADOS NA HORIZONTAL DE 11,5X19X19CM (ESPESSURA 11,5CM) DE PAREDES COM ÁREA LÍQUIDA MAIOR OU IGUAL A $6 M^{2}$ COM VÃOS E ARGAMASSA DE ASSENTAMENTO COM PREPARO MANUAL. AF_06/2014

CHAPISCO APLICADO EM ALVENARIA (SEM PRESENÇA DE VÃOS) E ESTRUTURAS DE CONCRETO DE FACHADA, COM ROLO PARA TEXTURA ACRÍLICA. ARGAMASSA TRAÇO 1:4 E EMULSÃO POLIMÉRICA (ADESIVO) COM PREPARO MANUAL. AF_06/2014

APLICAÇÃO MANUAL DE PINTURA COM TINTA LÁTEX ACRÍLICA EM PAREDES, DUAS DEMÃOS. $\mathrm{m}^{2}$ AF_06/2014

APLICAÇÃO MANUAL DE MASSA ACRÍLICA EM PAREDES EXTERNAS DE CASAS, DUAS DEMÃOS. $\quad \mathrm{m}^{2} \quad 12,7 \quad \mathrm{R} \$$ AF_05/2017

TRANA

PARA TELHA CERÂMICA CAPA-ANAL, INCLUSO

TELHAMENTO COM TELHA CERÂMICA CAPA-CANAL, TIPO COLONIAL, COM ATÉ 2 ÁGUAS, INCLUSO m

TRANSPORTE VERTICAL. AF_07/2019

CUMEEIRA PARA TELHA CERÂMICA EMBOÇADA COM ARGAMASSA TRAÇO 1:2:9 (CIMENTO, CAL E m

AREIA) PARA TELHADOS COM ATÉ 2 ÁGUAS, INCLUSO TRANSPORTE VERTICAL. AF_07/2019

$$
2019
$$$$
\begin{array}{lll}
\mathrm{m}^{2} & 25,9 & \mathrm{R} \$ \\
& 1 & 25,26 \\
\mathrm{~m}^{3} & 0,52 & \mathrm{R} \$
\end{array}
$$$$
\text { R\$ } 472,3
$$$$
2
$$$$
\mathrm{m}^{2} \quad 13,1 \quad \mathrm{R} \$
$$

250,23

$\mathrm{m}^{2} \quad 25,8 \quad \mathrm{R} \$$

$9 \quad 5,08$

$08 \quad 131,5$

$\begin{array}{llll}2 & \mathrm{R} \$ & \mathrm{R} \$\end{array}$

$2 \quad 10,39 \quad 132,16$

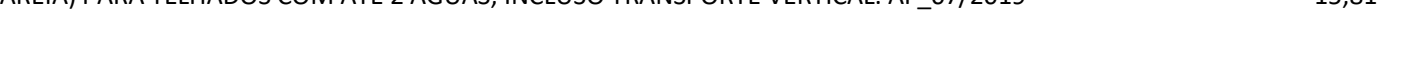


PI

87522 ALVENARIA DE VEDAÇÃO DE BLOCOS CERÂMICOS FURADOS NA HORIZONTAL DE 11,5X19X19CM

ISINA (ESPESSURA 11,5CM) DE PAREDES COM ÁREA LÍQUIDA MAIOR OU IGUAL A 6M² COM VÃOS E

PI ARGAMASSA DE ASSENTAMENTO COM PREPARO MANUAL. AF_06/2014

87530 MASSA ÚNICA, PARA RECEBIMENTO DE PINTURA, EM ARGAMASSA TRAÇO 1:2:8, PREPARO

ISINA MANUAL, APLICADA MANUALMENTE EM FACES INTERNAS DE PAREDES, ESPESSURA DE 20MM,

PI COM EXECUÇÃO DE TALISCAS. AF_06/2014

87888 CHAPISCO APLICADO EM ALVENARIA (SEM PRESENÇA DE VÃOS) E ESTRUTURAS DE CONCRETO DE

/SINA FACHADA, COM ROLO PARA TEXTURA ACRÍLICA. ARGAMASSA TRAÇO 1:4 E EMULSÃO POLIMÉRICA

PI (ADESIVO) COM PREPARO MANUAL. AF_06/2014

88487 APLICAÇÃO MANUAL DE PINTURA COM TINTA LÁTEX PVA EM PAREDES, DUAS DEMÃOS. $m^{2} \quad 82,9 \quad \mathrm{R} \$ \quad$ R\$

/SINA

PI

88489

/SINA

93392

/SINA

$\mathrm{PI}$

96135

/SINA

PI

Porta

s

91329

/SINA

PI

91331

/SINA

PI

Total

Geral

AF_06/2014

APLICAÇÃO MANUAL DE PINTURA COM TINTA LÁTEX ACRÍLICA EM PAREDES, DUAS DEMÃOS. AF_06/2014

REVESTIMENTO CERÂMICO PARA PAREDES INTERNAS COM PLACAS TIPO ESMALTADA PADRÃO POPULAR DE DIMENSÕES 20X20 CM, ARGAMASSA TIPO AC I, APLICADAS EM AMBIENTES DE ÁREA MENOR QUE 5 M2 NA ALTURA INTEIRA DAS PAREDES. AF_06/2014

APLICAÇÃO MANUAL DE MASSA ACRÍLICA EM PAREDES EXTERNAS DE CASAS, DUAS DEMÃOS. AF_05/2017

$\begin{array}{llll} & & 6 & \\ \mathrm{~m}^{2} & 71,9 & \mathrm{R} \$ & \mathrm{R} \$ \\ & 8 & 50,23 & 3.615,56 \\ \mathrm{~m}^{2} & 82,9 & \mathrm{R} \$ & \mathrm{R} \$ \\ & 2 & 29,44 & 2.441,16 \\ & & & \\ \mathrm{~m}^{2} & 143, & \mathrm{R} \$ & \mathrm{R} \$ \\ & 95 & 5,08 & 731,27 \\ \mathrm{~m}^{2} & 82,9 & \mathrm{R} \$ & \mathrm{R} \$ \\ & 2 & 8,17 & 677,46 \\ \mathrm{~m}^{2} & 46,3 & \mathrm{R} \$ & \mathrm{R} \$ \\ & 0 & 10,39 & 481,06 \\ & & & \\ \mathrm{~m}^{2} & 13,8 & \mathrm{R} \$ & \mathrm{R} \$ \\ & 2 & 35,21 & 486,60 \\ \mathrm{~m}^{2} & 46,2 & \mathrm{R} \$ & \mathrm{R} \$ \\ & 8 & 17,76 & 821,93 \\ & & & \mathrm{R} \$ \\ & & & \mathbf{2 . 7 4 8 , 8} \\ & & & \mathbf{3} \\ \text { un } & 1 & \mathrm{R} \$ & \mathrm{R} \$ \\ & & 527,1 & 527,11 \\ & & 1 & \mathrm{R} \$ \\ \text { un } & 4 & \mathrm{R} \$ & \mathrm{R} \\ & & 555,4 & 2.221,72 \\ & & 3 & \mathrm{R} \$ \\ & & & \mathbf{6 9 . 1 4 4} \\ & & & \mathbf{0 9}\end{array}$

KIT DE PORTA DE MADEIRA FRISADA, SEMI-OCA (LEVE OU MÉDIA), PADRÃO POPULAR, 60X210CM ESPESSURA DE 3CM, ITENS INCLUSOS: DOBRADIÇAS, MONTAGEM E INSTALAÇÃO DO BATENTE, SEM FECHADURA - FORNECIMENTO E INSTALAÇÃO. AF 08/2015

KIT DE PORTA DE MADEIRA FRISADA, SEMI-OCA (LEVE OU MÉDIA), PADRÃO POPULAR, 70X210CM, ESPESSURA DE 3CM, ITENS INCLUSOS: DOBRADIICAS, MONTAGEM E INSTALAÇÃO DO BATENTE, SEM FECHADURA - FORNECIMENTO E INSTALAÇÃO. AF_08/2015

09

Na sequência, parte-se para o Quadro Duração-Recursos, com o objetivo de estimar a duração dos serviços do cronograma, conforme se segue na tabela 2 .

Tabela 2: Quadro Duração-Recursos.

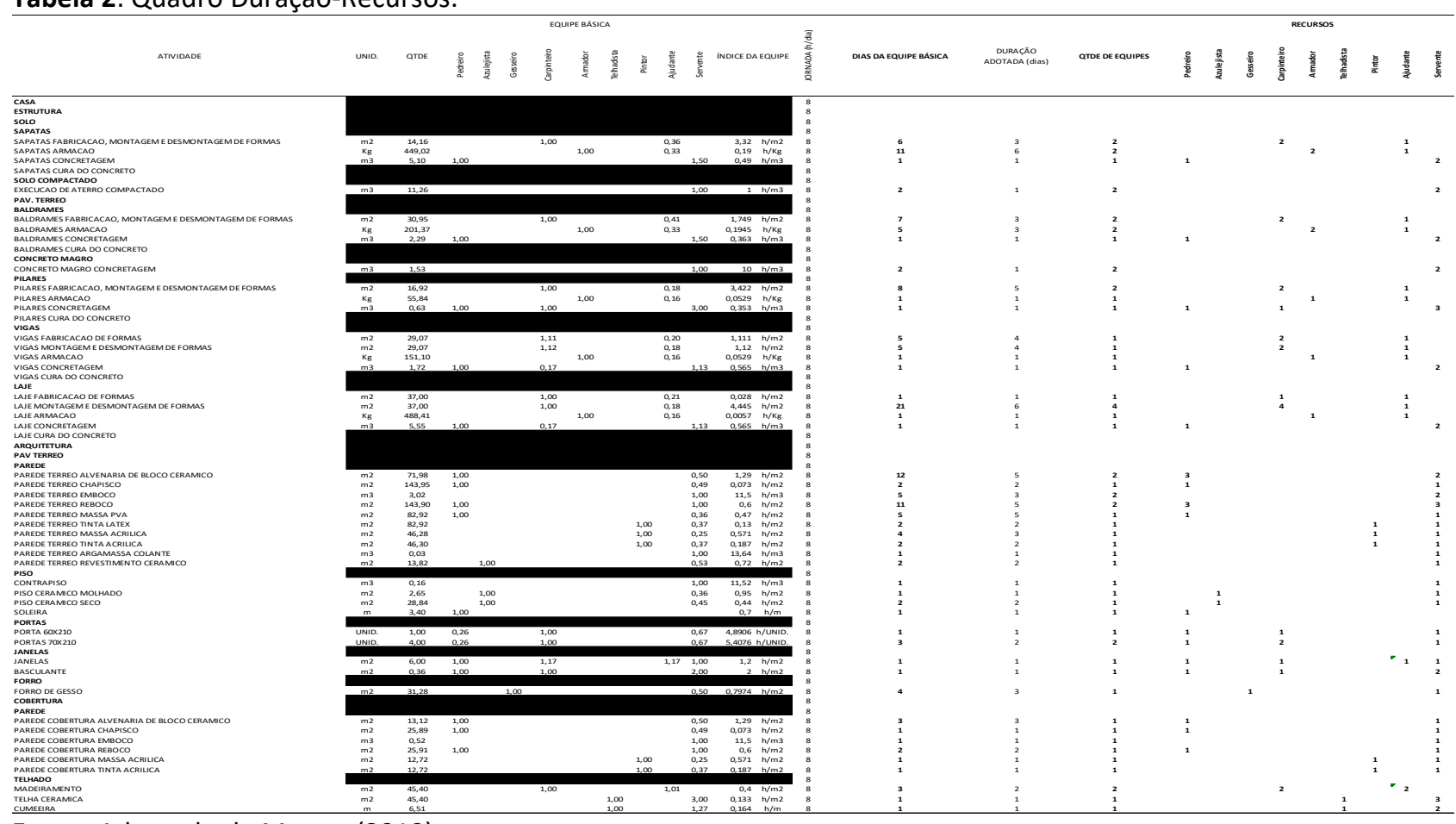

Fonte: Adaptado de Mattos (2010).

Com isso, parte-se para a criação do cronograma Gantt/PERT-CPM. Segue abaixo a programação planejada dos serviços, com seus recursos e custos, e o respectivo cronograma de barras com precedências 
(Tabela 3).

Tabela 3: Tabela do cronograma planejado retirada do MS Project.

\begin{tabular}{|c|c|c|c|c|c|c|c|c|}
\hline $\begin{array}{l}\text { Li } \\
\text { nh } \\
\text { a }\end{array}$ & $\begin{array}{l}\text { Predec } \\
\text { essora } \\
\mathrm{s}\end{array}$ & Nome da tarefa & $\begin{array}{l}\text { Dur } \\
\text { açã } \\
\text { o }\end{array}$ & Início & Término & $\begin{array}{l}\text { Crí } \\
\text { tic } \\
\text { a }\end{array}$ & Nome dos recursos & Custo \\
\hline 1 & & CASA & $\begin{array}{l}91 \\
\text { dias }\end{array}$ & $\begin{array}{l}30 / 09 / 2 \\
019 \\
09: 00\end{array}$ & $\begin{array}{l}27 / 01 / 2 \\
020 \\
18: 00\end{array}$ & $\begin{array}{l}\mathrm{Si} \\
\mathrm{m}\end{array}$ & & $\begin{array}{l}R \$ \\
69.14 \\
4,09\end{array}$ \\
\hline 2 & & ESTRUTURA & $\begin{array}{l}66 \\
\text { dias }\end{array}$ & $\begin{array}{l}30 / 09 / 2 \\
019 \\
09: 00\end{array}$ & $\begin{array}{l}26 / 12 / 2 \\
019 \\
15: 00\end{array}$ & $\begin{array}{l}\mathrm{Si} \\
\mathrm{m}\end{array}$ & & $\begin{array}{l}R \$ \\
40.09 \\
9,77\end{array}$ \\
\hline 3 & & SOLO & $\begin{array}{l}46 \\
\text { dias }\end{array}$ & $\begin{array}{l}\text { 30/09/2 } \\
019 \\
09: 00\end{array}$ & $\begin{array}{l}29 / 11 / 2 \\
019 \\
12: 00\end{array}$ & $\begin{array}{l}\mathrm{Si} \\
\mathrm{m}\end{array}$ & & $\begin{array}{l}\mathrm{R} \$ \\
10.05 \\
1,20\end{array}$ \\
\hline 4 & & SAPATAS & $\begin{array}{l}19 \\
\text { dias }\end{array}$ & $\begin{array}{l}30 / 09 / 2 \\
019 \\
09: 00\end{array}$ & $\begin{array}{l}23 / 10 / 2 \\
019 \\
11: 00\end{array}$ & $\begin{array}{l}\mathrm{Si} \\
\mathrm{m}\end{array}$ & & $\begin{array}{l}\mathrm{R} \$ \\
9.878 \\
58\end{array}$ \\
\hline 5 & 6 & $\begin{array}{l}\text { SAPATAS FABRICACAO, } \\
\text { MONTAGEM E DESMONTAGEM DE } \\
\text { FORMAS }\end{array}$ & $\begin{array}{l}2 \\
\text { dias }\end{array}$ & $\begin{array}{l}04 / 10 / 2 \\
019 \\
09: 00\end{array}$ & $\begin{array}{l}07 / 10 / 2 \\
019 \\
10: 00\end{array}$ & $\begin{array}{l}\text { Nã } \\
\text { ○ }\end{array}$ & $\begin{array}{l}\text { FAB, MONT E DESM FORMAS SAPATAS } \\
{\left[14,16 \mathrm{~m}^{2}\right] \text {; Carpinteiro [2]; Ajudante }}\end{array}$ & $\begin{array}{l}\mathrm{R} \$ \\
2.041 \\
87\end{array}$ \\
\hline 6 & & SAPATAS ARMACAO & $\begin{array}{l}4 \\
\text { dias }\end{array}$ & $\begin{array}{l}30 / 09 / 2 \\
019 \\
09: 00\end{array}$ & $\begin{array}{l}03 / 10 / 2 \\
019 \\
18: 00\end{array}$ & $\begin{array}{l}\mathrm{Si} \\
\mathrm{m}\end{array}$ & $\begin{array}{l}\text { ARMACAO SAPATAS[449,02 Kg]; } \\
\text { Armador[2]; Ajudante }\end{array}$ & $\begin{array}{l}\mathrm{R} \$ \\
5.931 \\
55\end{array}$ \\
\hline 7 & 6 & SAPATAS CONCRETAGEM & $\begin{array}{l}1 \\
\text { dia }\end{array}$ & $\begin{array}{l}04 / 10 / 2 \\
019 \\
09: 00\end{array}$ & $\begin{array}{l}04 / 10 / 2 \\
019 \\
18: 00\end{array}$ & $\begin{array}{l}\mathrm{Si} \\
\mathrm{m}\end{array}$ & $\begin{array}{l}\left.\text { CONCRETAGEM SAPATAS[5,1 } \mathrm{m}^{3}\right] ; \\
\text { Pedreiro; Servente[2] }\end{array}$ & $\begin{array}{l}\mathrm{R} \$ \\
1.905, \\
16\end{array}$ \\
\hline 8 & 7 & SAPATAS CURA DO CONCRETO & $\begin{array}{l}14 \\
\text { dias }\end{array}$ & $\begin{array}{l}05 / 10 / 2 \\
019 \\
09: 00\end{array}$ & $\begin{array}{l}23 / 10 / 2 \\
019 \\
11: 00\end{array}$ & $\begin{array}{l}\mathrm{Si} \\
\mathrm{m}\end{array}$ & & $\begin{array}{l}\mathrm{R} \$ \\
0,00\end{array}$ \\
\hline 9 & & SOLO COMPACTADO & $\begin{array}{l}1 \\
\text { dia }\end{array}$ & $\begin{array}{l}28 / 11 / 2 \\
019 \\
13: 00\end{array}$ & $\begin{array}{l}29 / 11 / 2 \\
019 \\
12: 00\end{array}$ & $\begin{array}{l}\text { Nã } \\
\text { o }\end{array}$ & & $\begin{array}{l}\mathrm{R} \$ \\
172,6 \\
2\end{array}$ \\
\hline 10 & 23 & $\begin{array}{lll}\text { EXECUCAO } & \text { DE } & \text { ATERRO } \\
\text { COMPACTADO } & & \end{array}$ & $\begin{array}{l}1 \\
\text { dia }\end{array}$ & $\begin{array}{l}28 / 11 / 2 \\
019 \\
13: 00\end{array}$ & $\begin{array}{l}29 / 11 / 2 \\
019 \\
12: 00\end{array}$ & $\begin{array}{l}\text { Nã } \\
\text { o }\end{array}$ & $\begin{array}{l}\text { COMPACTACAO SOLO[11,26 } \\
\text { Servente[2] }\end{array}$ & $\begin{array}{l}R \$ \\
172,6 \\
2\end{array}$ \\
\hline 11 & & PAV. TERREO & $\begin{array}{l}66 \\
\text { dias }\end{array}$ & $\begin{array}{l}30 / 09 / 2 \\
019 \\
09: 00\end{array}$ & $\begin{array}{l}26 / 12 / 2 \\
019 \\
15: 00\end{array}$ & $\begin{array}{l}\text { Nã } \\
\text { o }\end{array}$ & & $\begin{array}{l}R \$ \\
30.04 \\
8,57\end{array}$ \\
\hline 12 & & BALDRAMES & $\begin{array}{l}17 \\
\text { dias }\end{array}$ & $\begin{array}{l}23 / 10 / 2 \\
019 \\
11: 00\end{array}$ & $\begin{array}{l}16 / 11 / 2 \\
019 \\
11: 00\end{array}$ & $\begin{array}{l}\mathrm{Si} \\
\mathrm{m}\end{array}$ & & $\begin{array}{l}R \$ \\
5.532 \\
42\end{array}$ \\
\hline 13 & 14 & $\begin{array}{l}\text { BALDRAMES FABRICACAO, } \\
\text { MONTAGEM E DESMONTAGEM DE } \\
\text { FORMAS }\end{array}$ & $\begin{array}{l}2 \\
\text { dias }\end{array}$ & $\begin{array}{l}25 / 10 / 2 \\
019 \\
11: 00\end{array}$ & $\begin{array}{l}29 / 10 / 2 \\
019 \\
11: 00\end{array}$ & $\begin{array}{l}\text { Nã } \\
\text { o }\end{array}$ & $\begin{array}{l}\text { FAB, MONT E DESM. FORMAS } \\
\text { BALDRAMES[30,95 } \mathrm{m}^{2} \text { ]; Carpinteiro[2]; } \\
\text { Ajudante }\end{array}$ & $\begin{array}{l}\mathrm{R} \$ \\
2.044 \\
56\end{array}$ \\
\hline 14 & 8 & BALDRAMES ARMACAO & $\begin{array}{l}2 \\
\text { dias }\end{array}$ & $\begin{array}{l}23 / 10 / 2 \\
019 \\
11: 00\end{array}$ & $\begin{array}{l}25 / 10 / 2 \\
019 \\
11: 00\end{array}$ & $\begin{array}{l}\mathrm{Si} \\
\mathrm{m}\end{array}$ & $\begin{array}{l}\text { ARMACAO BALDRAMES[201,37 Kg]; } \\
\text { Armador[2]; Ajudante }\end{array}$ & $\begin{array}{l}\mathrm{R} \$ \\
2.660, \\
10\end{array}$ \\
\hline 15 & 14 & BALDRAMES CONCRETAGEM & $\begin{array}{l}1 \\
\text { dia }\end{array}$ & $\begin{array}{l}25 / 10 / 2 \\
019 \\
11: 00\end{array}$ & $\begin{array}{l}28 / 10 / 2 \\
019 \\
11: 00\end{array}$ & $\begin{array}{l}\mathrm{Si} \\
\mathrm{m}\end{array}$ & $\begin{array}{l}\left.\text { CONCRETAGEM BLADRAMES[2,29 } \mathrm{m}^{3}\right] \text {; } \\
\text { Pedreiro; Servente[2] }\end{array}$ & $\begin{array}{l}R \$ \\
827,7 \\
7\end{array}$ \\
\hline 16 & 15 & BALDRAMES CURA DO CONCRETO & $\begin{array}{l}14 \\
\text { dias }\end{array}$ & $\begin{array}{l}28 / 10 / 2 \\
019 \\
11: 00\end{array}$ & $\begin{array}{l}16 / 11 / 2 \\
019 \\
11: 00\end{array}$ & $\begin{array}{l}\mathrm{Si} \\
\mathrm{m}\end{array}$ & & $\begin{array}{l}\mathrm{R} \$ \\
0,00\end{array}$ \\
\hline 17 & & CONCRETO MAGRO & $\begin{array}{l}1 \\
\text { dia }\end{array}$ & $\begin{array}{l}29 / 11 / 2 \\
019 \\
13: 00\end{array}$ & $\begin{array}{l}30 / 11 / 2 \\
019 \\
12: 00\end{array}$ & $\begin{array}{l}\text { Nã } \\
\text { o }\end{array}$ & & $\begin{array}{l}R \$ \\
557,0 \\
0\end{array}$ \\
\hline 18 & 10 & CONCRETO MAGRO CONCRETAGEM & $\begin{array}{l}1 \\
\text { dia }\end{array}$ & $\begin{array}{l}29 / 11 / 2 \\
019 \\
13: 00\end{array}$ & $\begin{array}{l}30 / 11 / 2 \\
019 \\
12: 00\end{array}$ & $\begin{array}{l}\text { Nã } \\
\text { o }\end{array}$ & $\begin{array}{l}\text { CONCRETAGEM CONCRETO } \\
\left.\text { MAGRO[1,53 } \mathrm{m}^{3}\right] ; \text { Servente[2] }\end{array}$ & $\begin{array}{l}R \$ \\
557,0 \\
0\end{array}$ \\
\hline 19 & & PILARES & $\begin{array}{l}45 \\
\text { dias }\end{array}$ & $\begin{array}{l}\text { 30/09/2 } \\
019 \\
09: 00\end{array}$ & $\begin{array}{l}28 / 11 / 2 \\
019 \\
12: 00\end{array}$ & $\begin{array}{l}\text { Nã } \\
\text { o }\end{array}$ & & $\begin{array}{l}\mathrm{R} \$ \\
3.443 \\
46\end{array}$ \\
\hline 20 & & $\begin{array}{l}\text { PILARES FABRICACAO, MONTAGEM } \\
\text { E DESMONTAGEM DE FORMAS }\end{array}$ & $\begin{array}{l}5 \\
\text { dias }\end{array}$ & $\begin{array}{l}30 / 09 / 2 \\
019 \\
09: 00\end{array}$ & $\begin{array}{l}04 / 10 / 2 \\
019 \\
18: 00\end{array}$ & $\begin{array}{l}\text { Nã } \\
\text { o }\end{array}$ & $\begin{array}{l}\text { FAB, MONT E DESM FORMAS } \\
\left.\text { PILARES[16,92 } \mathrm{m}^{2}\right] \text {; Carpinteiro[2] }\end{array}$ & $\begin{array}{l}\mathrm{R} \$ \\
2.850 \\
17\end{array}$ \\
\hline 21 & 16 & PILARES ARMACAO & $\begin{array}{l}1 \\
\text { dia }\end{array}$ & $\begin{array}{l}16 / 11 / 2 \\
019 \\
11: 00\end{array}$ & $\begin{array}{l}18 / 11 / 2 \\
019 \\
12: 00\end{array}$ & $\begin{array}{l}\mathrm{Si} \\
\mathrm{m}\end{array}$ & ARMACAO PILARES[55,84 Kg]; Armador & $\begin{array}{l}\mathrm{R} \$ \\
395,9 \\
1\end{array}$ \\
\hline 22 & 21 & PILARES CONCRETAGEM & $\begin{array}{l}1 \\
\text { dia }\end{array}$ & $\begin{array}{l}18 / 11 / 2 \\
019 \\
13: 00\end{array}$ & $\begin{array}{l}19 / 11 / 2 \\
019 \\
12: 00\end{array}$ & $\begin{array}{l}\mathrm{Si} \\
\mathrm{m}\end{array}$ & $\begin{array}{l}\text { CONCRETAGEM PILARES[0,63 } \mathrm{m}^{3} \text { ]; } \\
\text { Carpinteiro; Pedreiro; Servente[3] }\end{array}$ & $\begin{array}{l}\mathrm{R} \$ \\
197,3 \\
8\end{array}$ \\
\hline 23 & 22 & PILARES CURA DO CONCRETO & $\begin{array}{l}7 \\
\text { dias }\end{array}$ & $\begin{array}{l}19 / 11 / 2 \\
019\end{array}$ & $\begin{array}{l}28 / 11 / 2 \\
019\end{array}$ & $\begin{array}{l}\mathrm{Si} \\
\mathrm{m}\end{array}$ & & $\begin{array}{l}\mathrm{R} \$ \\
0,00\end{array}$ \\
\hline
\end{tabular}




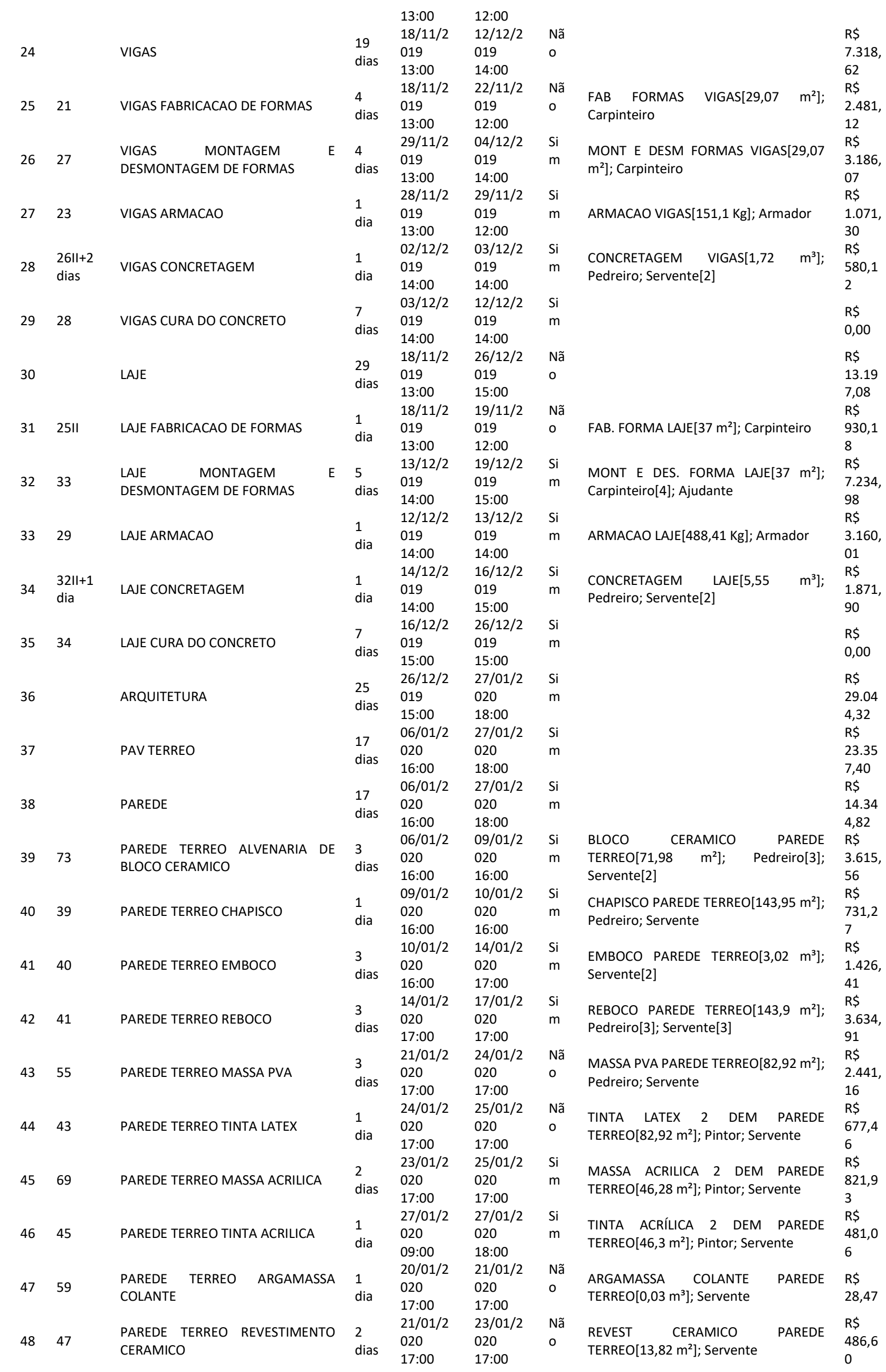




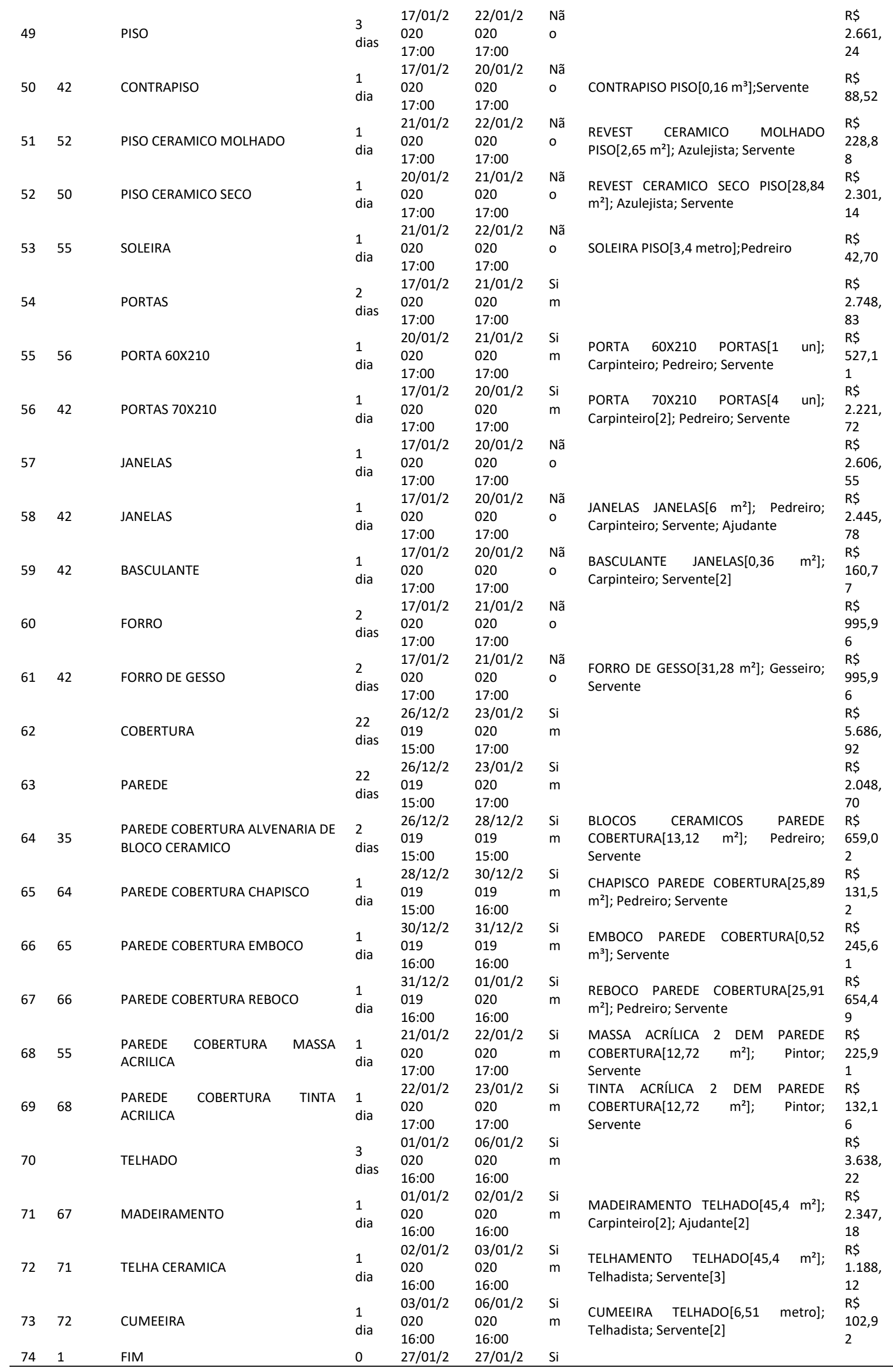




$\begin{array}{lll}\text { dias } & 020 & 020 \\ & 18: 00 & 18: 00\end{array}$
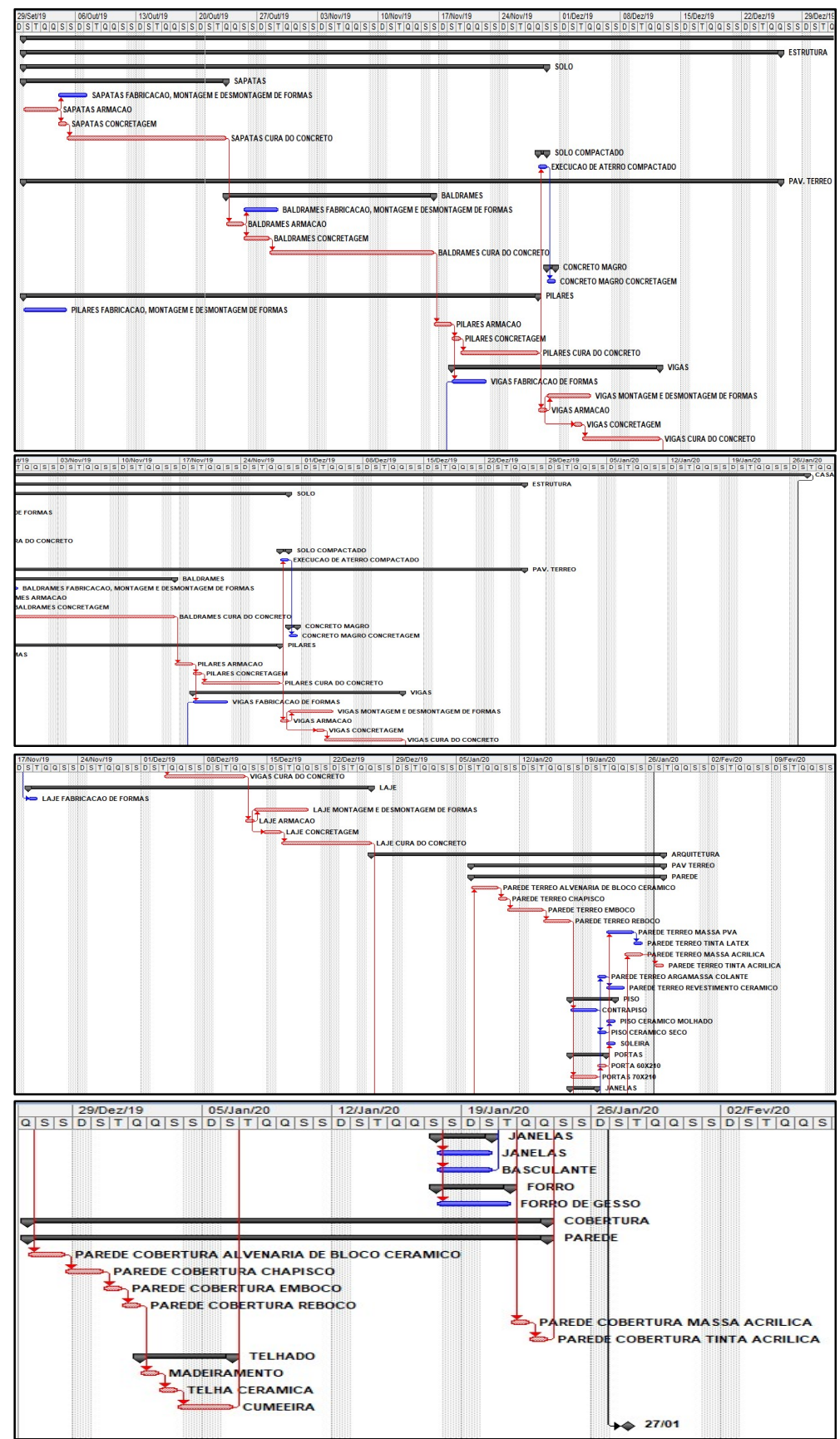

Figura 8: Cronograma Gantt/PERT-COM.

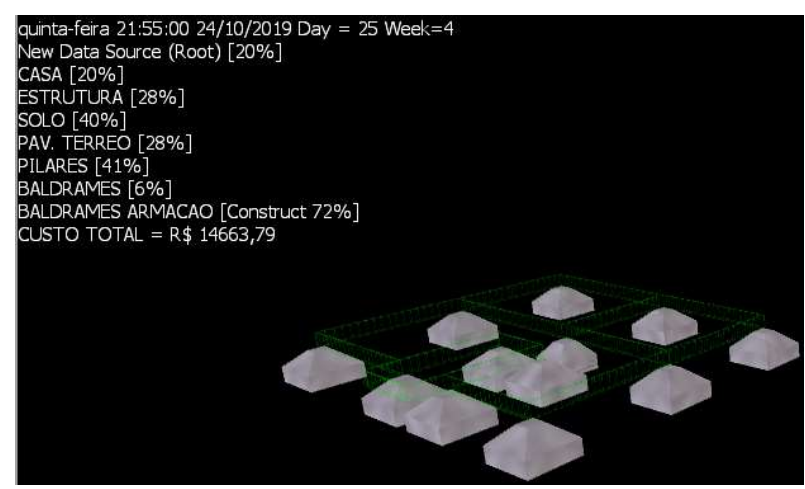

Figura 9: Simulação do projeto no Navisworks Andamento da armação das vigas baldrames 24/10/2019.

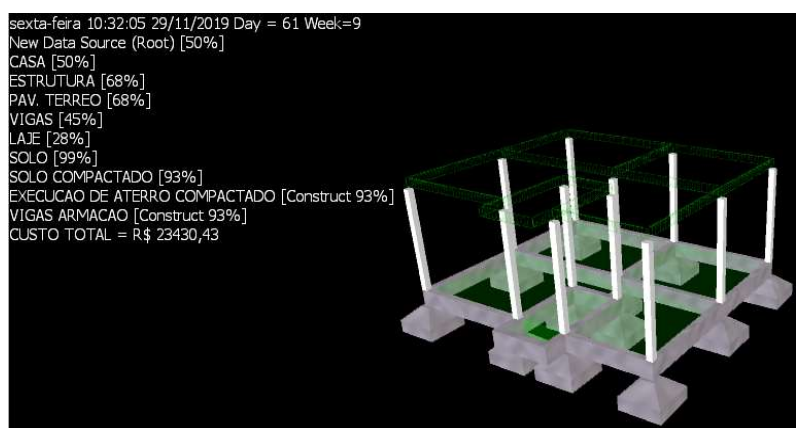

Figura 10: Simulação do projeto no Navisworks Andamento da armação das vigas e do aterro compactado - 29/11/2019. 


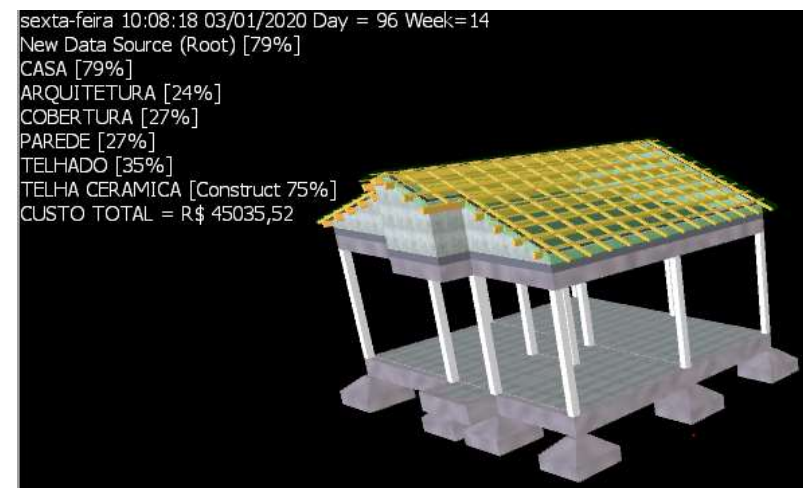

Figura 11: Simulação do projeto no Navisworks Término do madeiramento e andamento do telhamento $-03 / 01 / 2020$.

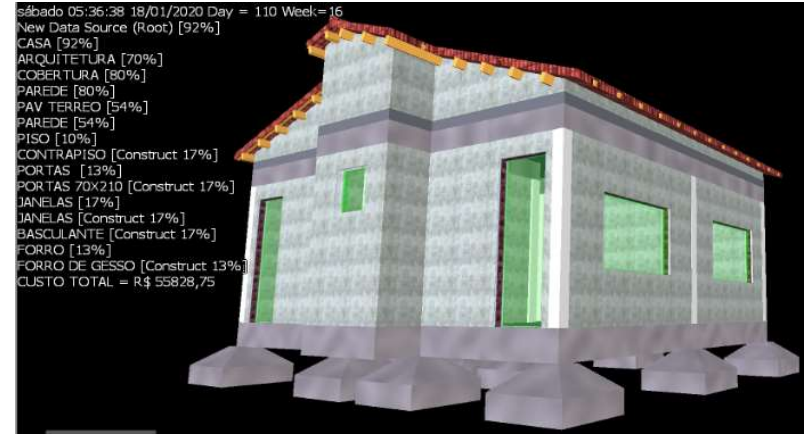

Figura 13: Simulação do projeto no Navisworks Andamento do contrapiso, portas, janelas e forro de gesso - 18/01/2020.

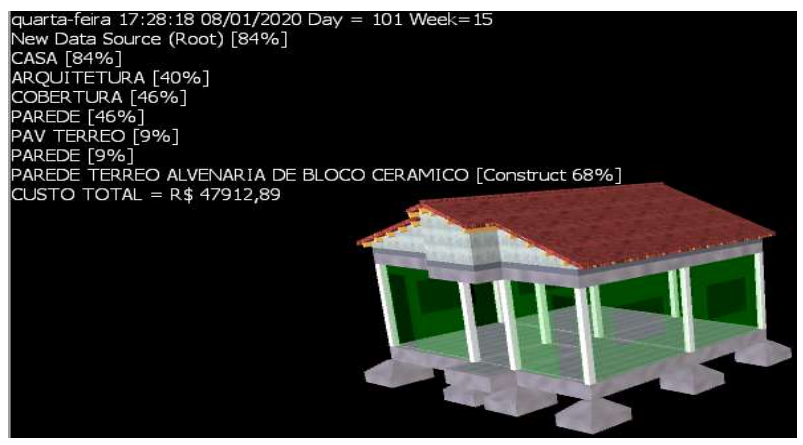

Figura 12: Simulação do projeto no Navisworks Andamento do assentamento de blocos cerâmicos no pavimento térreo -08/01/2020.

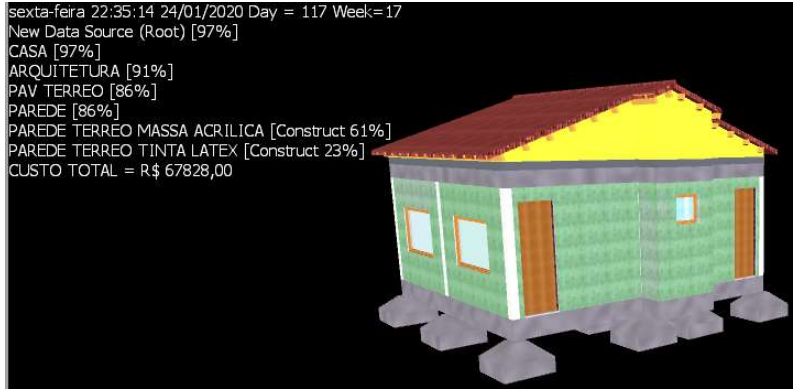

Figura 14: Simulação do projeto no Navisworks Término da pintura externa das paredes de cobertura, andamento da aplicação de pintura interna e de massa acrílica das paredes externas do pavimento térreo $24 / 01 / 2020$

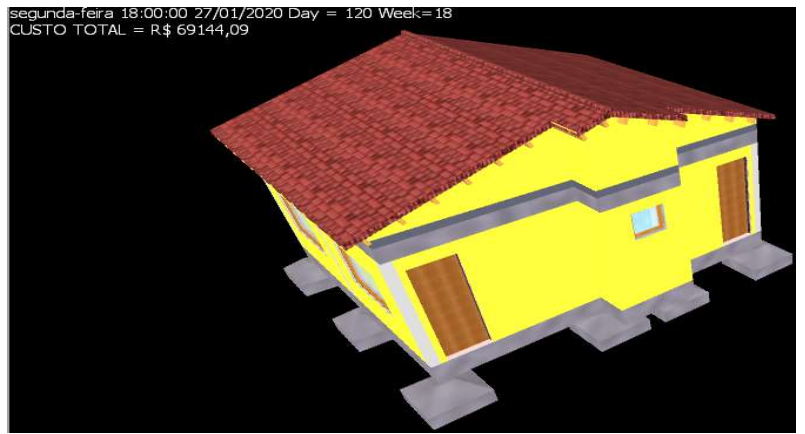

Figura 15: Simulação do projeto no Navisworks - Término da obra - 27/01/2020.

Finalmente, após elaborado o modelo tridimensional e preparado o cronograma, o que se fez foi exportar ambos para o software Navisworks 2019 e, após feitas as vinculações de cada elemento tridimensional à tarefa correspondente, simulou-se a sequência de atividades em cada momento do projeto, conforme se observa nas figuras $9,10,11,12,13,14,15$.

Expressando finalmente o objetivo deste trabalho, as vantagens proferidas pelo BIM 4D comparadas às do processo convencional de planejamento foram as seguintes:

I - Facilidade de visualização da sequência de tarefas: Muitas vezes, durante o sequenciamento tradicional de tarefas, o trabalho imaginativo, quando se observa somente o cronograma em barras, tem grande risco de ser falho, pois pode se estabelecer precedências errôneas e, com isso, a sequência de serviços estar incoerente com a exercida em campo. O planejamento em BIM 4D vem justamente para diminuir ou mesmo dirimir este problema, visto que, conforme visto acima, o seguimento das atividades agora é feito de 
maneira virtual e rapidamente é possível identificar possíveis incongruências neste, caso haja.

II - Facilitação da visualização de projetos tridimensionalmente: Antes, com a elaboração de plantas baixas de cada disciplina no projeto convencional, muitas vezes necessitava-se de um esforço mental significativo e, algumas vezes, de experiência e conhecimento técnico suficiente para conseguir imaginar cada elemento disposto no espaço e suas possíveis implicações. Além desta preocupação, tentava-se identificar possíveis choques entre disciplinas com desenhos vistos separadamente, sem contar com o fato de cada projetista realizar o seu projeto sem se comunicar com o outro. No entanto, em momentos não raros era inconcebível identificar todos os conflitos entre projetos em virtude das limitações do racional humano, o que infelizmente era somente observado durante a execução no canteiro. O problema disso era que este reconhecimento tardio acabava por onerar determinado empreendimento, pois além de exigir mudança de projeto, a depender da inconformidade, era impossível dar sequência às atividades pelo fato de estes elementos em conflito serem precedentes da próxima atividade. O planejamento BIM 4D veio para resolver este problema, pois no tocante à visão 3D de cada projeto, esta vai sendo criada simultaneamente ao desenho 2D, e também eliminando de pauta a disposição de elementos de projeto mentalmente. Em resumo, isso reduz esforço intelectual e tempo para a elaboração de projetos, além de adversidades serem identificadas antes da etapa de execução, o que reduz custo e aumenta a produtividade em campo.

III - Simulação gráfica do planejamento: Assim como a dificuldade em visualizar possível conflito entre disciplinas quando se há somente planta baixa e cortes, sem a possibilidade de vinculação entre elas, o planejamento elaborado somente no formato de barras e setas indicando atividades precedentes e sucessivas exige qualificação e experiência do profissional, e mesmo assim, há grande risco de alguma sequência ser incoerente. Além disso, o trabalho de planejar torna-se mais árduo e longo até se ter a certeza da sucessão de serviços. O BIM 4D, mais uma vez, entra neste cenário para facilitar o trabalho de planejamento e ainda ser acessível à compreensão de leigos na área, visto que a visualização gráfica permite a noção instantânea da qualidade do cronograma. Outrossim, o intuito dessa dimensão não é apenas informar que o cronograma de Gantt está coerente. Esta nova metodologia permite criar diversos outros cronogramas de planejamento até ser eleito um menos oneroso e relevantemente produtivo, o que pode ser feito com a reunião de todos os participantes de determinado projeto. Em outras palavras, O BIM 4D, inclusive, exige o engajamento de todos os stakeholders.

IV - Geração automática de orçamento e quantitativo em qualquer fase da obra: Durante o sequenciamento das tarefas na simulação do cronograma, o planejamento BIM 4D permite a geração automática dos custos e quantidades em determinado momento da simulação (SILVA, 2017). Portanto, à medida que se aperfeiçoa o projeto, o quantitativo e o orçamento são automaticamente extraídos.

V - Identificação de conflitos de espaço e tempo: O planejamento BIM 4D permite a rápida identificação de conflitos de espaço e tempo, gerando uma resposta rápida a possíveis entraves na sequência de atividades, o que não se é feito com o planejamento convencional, pois este exige que apenas haja especulação contra possíveis conflitos desse tipo, e não a certeza abarcada pelo BIM 4D (SILVA, 2017).

VI - Ferramenta viável para a introdução da construção enxuta: A construção enxuta vem alinhada à 
metodologia BIM, visto que se exige experiência, muitas vezes insucessos iniciais, até se chegar à precisão e ao sucesso da sua aplicação. O seu objetivo é justamente o aumento da produtividade e controle de estoque de materiais com a aplicação do sistema de produção puxada nos canteiros de obra, de modo a reduzir custos substancialmente. Para isso, exige-se precisão da informação e resposta rápida a determinados contratempos de campo. A ferramenta BIM 4D vem, neste sentido, como útil e necessária para este novo processo de construção, já que emite dados imediatos e precisos no seu cronograma, de modo a colaborar no prosseguimento das atividades do sistema lean de construção.

VII - Planejamento de canteiro de obras: O processo BIM 4D, além de simular visualmente as atividades do empreendimento, planeja eficazmente a circulação de materiais e equipamentos de transporte dentro do canteiro de obras. Outrossim, permite localizar pontos ótimos de armazenamento de insumos (SILVA, 2017). Assim, é um processo eficaz para o planejamento das atividades de canteiro, o que não se é possível no processo convencional, ou designa um trabalho dificultoso para tal.

\section{CONCLUSÕES}

A nova metodologia BIM veio para inovar o conceito de leitura de projetos, de elaboração de planejamento, orçamento e gerenciamento, além de ocasionar uma inter-relação entre todos os envolvidos, fato não presente na construção civil há um bom tempo. Dentre todas essas mudanças, o importante é: ela veio para otimizar todas as etapas da construção. No entanto, tal processo exige mudança brusca de paradigmas culturais e comportamentais, o que dificulta a sua implantação, pois ainda se há um egoísmo e medo de se abrir a tudo o que é novo, já que, de início, geram-se aumento de custo, tempo e conhecimento, o que não é recepcionado positivamente entre os que ainda querem manter as velhas práticas.

O BIM é um 'mundo' a ser explorado e ainda não se alcançou todo o seu potencial, mas o que se sabe é: não há mais como retroagir e o BIM veio para ficar. Neste trabalho, pudemos experimentar a aplicação de uma das dimensões dele, que foi a 4D (tempo), responsável pelo planejamento. Convém notar que o objetivo deste artigo foi fazer uma simples comparação entre o processo convencional e o novo método de planejamento BIM 4D. Explorou-se também a etapa de orçamentação, mas foi realçado que não é a maneira ideal para isso, devido à complexidade desta área, o que se exigem outros softwares BIM para a geração dos custos. Estes foram inseridos no tal projeto apenas para demonstrar que, durante a simulação gráfica da sequenciação de atividades, os custos vão também sendo simulados junto com ela e variando conforme cada momento da sequência, concluindo-se como um benefício relevante comparado ao planejamento convencional, pois este não faz esta atualização automática.

Em consequência, este trabalho abre caminhos para novas pesquisas na mesma área do conhecimento, de maneira a levantar outras vantagens da dimensão 4D perante a tradicional. Ademais, não somente nesta extensão, mas outras dimensões da metodologia BIM poderão ser minuciadas, além de explorar as inter-relações entre elas e comparar com os métodos usuais.

Por fim, tal projeto atendeu a expectativa de comprovar que há benefícios relevantes da aplicação da dimensão 4D e que é necessária mudança nos padrões daquilo que se enxerga atualmente como 
planejamento e gerenciamento de atividades concernentes à área da construção civil. O BIM 4D é um facilitador, mas ao mesmo tempo fornecedor de muitas informações, sendo necessário saber lidar com todas elas e utilizá-las no momento preciso de cada etapa deste módulo.

\section{REFERÊNCIAS}

BIOTTO, C. N.; FORMOSO, C. T.; ISATTO, E. L.. Método para o uso da modelagem BIM 4D na gestão da produção em empreendimentos de construção. In: SIMPÓSIO BRASILEIRO DE QUALIDADE DO PROJETO NO AMBIENTE CONSTRUÍDO,3; ENCONTRO DE TECNOLOGIA DE INFORMAÇÃO E COMUNICAÇÃO NA CONSTRUÇÃO, 6. Anais. Campinas, 2013. p.882-893.

BRITO, D. M.; FERREIRA, E. A. M.. Avaliação de estratégias para representação e análise do planejamento e controle de obras utilizando modelos BIM 4D. Associação Nacional de Tecnologia do Ambiente Construído, São Paulo, v.15, n.4, p.203-223, 2015. DOI: http://dx.doi.org/10.1590/s1678$\underline{86212015000400047}$

CALDAS, L. R.; NASCIMENTO, M. L. M.; CARVALHO, M. T. M.; SPOSTO, R. M.. Diagnóstico da produção científica relacionada à aplicação do BIM à metodologia de avaliação do ciclo de vida (ACV). In: IBERIAN LATIN-AMERICAN CONGRESS ON COMPUTATIONAL METHODS IN ENGINEERING, 36. Anais. Rio de Janeiro, 2015.

CAMPESTRINI, T. F.; GARRIDO, M. C.; MENDES JUNIOR, R.; SCHEER, S.; FREITAS, M. C. D.. Entendendo BIM. Curitiba: UFPR, 2015.

EASTMAN, C.; TEICHOLZ, P.; SACKS, R.; LISTON, K.. Bim Handbook: A Guide to Building Information Modeling for Owners, Managers, Designers, Engineers and Contractors. 2 ed. WILEY, 2011. p.99-149.

FORMOSO, C. T.; BERNARDES, M. M. S.; ALVES, T. C. L.; OLIVEIRA, K. A.. Planejamento e controle da produção em empresas de construção. Porto Alegre: Universidade Federal do Rio Grande do Sul, 2001.
GEHBAUER, F.; EGGENSPERGER, M.; NEWTON, S. A.. Planejamento prévio da execução. In: GEHBAUER, F.; EGGENSPERGER, M.; NEWTON, S. A.. Planejamento e gestão de obras: Um resultado prático da cooperação técnica Brasil-Alemanha. 2 ed. Curitiba: CEFET, 2002. p.271-318.

MAGALHÃES, L. S.; FARIAS, S. S.. Plataforma BIM integrado ao planejamento 4D na construção civil. Dissertação (Mestrado em Engenharia de Produção) - Universidade Federal do Pará, Fortaleza, 2018.

MATTOS, A. D.. Planejamento e controle de obras. São Paulo: PINI, 2010.

MAYERLE, S. F.. Programação de projetos com PERT/CPM. Florianópolis: Universidade Federal de Santa Catarina, 2014.

QUEIROZ, M. N.. Programação e controle de obras. Juiz de Fora: Universidade Federal de Juiz de Fora, 2001.

QUEZADO, P. C. A. M.. Programação do fluxo produtivo de máquinas e equipamentos para moinhos sob encomenda utilizando PERT/COM e heurísticas. Dissertação (Mestrado em Engenharia) - Universidade Federal de Santa Catarina, Florianópolis, 1999.

SILVA, C. P.. A plataforma BIM aplicada no planejamento de obras. Monografia (Bacharelado em Engenharia Civil) Universidade de Brasília, Brasília, 2017.

SMARTSHEET. Modelo de projeto do gráfico de Gantt. In: SMARTSHEET. Os melhores modelos de gerenciamento de projeto do Excel. SMARTSHEET, 2019.

A CBPC - Companhia Brasileira de Produção Científica (CNPJ: 11.221.422/0001-03) detém os direitos materiais desta publicação. Os direitos referem-se à publicação do trabalho em qualquer parte do mundo, incluindo os direitos às renovações, expansões e disseminações da contribuição, bem como outros direitos subsidiários. Todos os trabalhos publicados eletronicamente poderão posteriormente ser publicados em coletâneas impressas sob coordenação da Sustenere Publishing, da Companhia Brasileira de Produção Científica e seus parceiros autorizados. Os (as) autores (as) preservam os direitos autorais, mas não têm permissão para a publicação da contribuição em outro meio, impresso ou digital, em português ou em tradução. 